\title{
Time-dependent degree of conversion, Martens parameters, and flexural strength of different dual-polymerizing resin composite luting materials
}

\author{
Matthias Kelch $^{1}$ (D) $\cdot$ Bogna Stawarczyk ${ }^{1} \cdot$ Felicitas Mayinger $^{1}$
}

Received: 23 January 2021 / Accepted: 19 July 2021 / Published online: 3 August 2021

(c) The Author(s) 2021

\begin{abstract}
Objective To investigate the degree of conversion (DC), Martens hardness (HM), elastic indentation modulus ( $\mathrm{E}_{\mathrm{IT}}$ ), and biaxial flexural strength (BFS) of six dual-polymerizing resin composite luting materials initially and after 2 and 7 days of aging.

Materials and methods Specimens fabricated from Bifix QM (BIF; VOCO), Calibra Ceram (CAL; Dentsply Sirona), DuoCem (DUO; Coltène/Whaledent), G-CEM LinkForce (GCE; GC Europe), PANAVIA V5 (PAN; Kuraray Europe), and Variolink Esthetic DC (VAR; Ivoclar Vivadent) ( $n=12$ per material) were light-polymerized through $1 \mathrm{~mm}$ thick discs (Celtra Duo, Dentsply Sirona). DC, HM, and $\mathrm{E}_{\mathrm{IT}}$ were recorded directly after fabrication, and after 2 and 7 days of aging. As a final test, BFS was measured. Univariate ANOVAs, Kruskal-Wallis, Mann-Whitney $U$, Friedman, and Wilcoxon tests, and Weibull modulus were computed $(p<0.05)$.

Results While CAL presented low DC, HM, $\mathrm{E}_{\mathrm{IT}}$, and BFS values, DUO and BIF showed high results. Highest Weibull moduli were observed for VAR and DUO. DC and Martens parameters increased between the initial measurement and 2 days of aging, while aging for 7 days provided no further improvement.

Conclusions The choice of dual-polymerizing resin composite luting material plays an important role regarding chemical and mechanical properties, especially with patients sensitive to toxicological issues. DUO may be recommended for bonding fixed dental prostheses, as it demonstrated significantly highest and reliable results regarding DC, HM, and BFS. As DC and HM showed an increase in the first $48 \mathrm{~h}$, it may be assumed that the polymerization reaction is not completed directly after initial polymerization, which is of practical importance to dentists and patients.

Clinical relevance The chemical and mechanical properties of dual-polymerizing resin composite luting materials influence the overall stability and long-term performance of the restoration.
\end{abstract}

Keywords Dual-polymerizing resin composite luting materials $\cdot$ Raman spectroscopy $\cdot$ Degree of conversion $\cdot$ Martens hardness $\cdot$ Elastic indentation modulus $\cdot$ Biaxial flexural strength

\section{Introduction}

In the case of substance or tooth loss, fixed dental prostheses (FDPs) made of tooth-colored materials (e.g., ceramic or highperformance polymers) or conventional metal alloys represent a common treatment option to restore function and esthetics in the oral cavity [1]. To ensure long-term success, the intraoral

Matthias Kelch

matthias.kelch@med.uni-muenchen.de

1 Department of Prosthetic Dentistry, University Hospital, LMU Munich, Goethestrasse 70, 80336 Munich, Germany fixation of restorations fabricated in the dental laboratory is of paramount importance [2,3]. The choice of luting agent depends on numerous factors such as the restorative material and the specific clinical situation [4]. While the use of FDPs in the anterior region may require a high translucency on part of the luting material, deep subgingival defects in the posterior region that impede drainage can call for the use of conventional cements [5]. In this extensive field, resin composite luting materials aim to combine outstanding optical and mechanical properties. Advantages include an improved retention and seal of margin, a negligible solubility, and the preservation of dental hard tissue, as macro retentive preparations become obsolete [6]. The development of dual-polymerizing 
resin composite luting material allows a quick sealing of the restoration margins, which is crucial for clinical settings presenting themselves with a challenging drainage situation [7]. Self-polymerizing initiators aim to enable a comprehensive conversion of the luting agent in situations, where the restoration material is too thick or opaque to allow the transmission of light [8]. An insufficient degree of conversion (DC) can increase the solubility of resin composite luting materials and entail microleakage at the restoration margins [9], which can in the long run cause an undermining formation of caries that can result in the total failure of the restoration [10,11]. An insufficient polymerization may furthermore reduce the color stability of the luting material and impair the bond strength to natural tooth substances $[12,13]$. In addition, a low DC can compromise biocompatibility, an important factor when regarding the ever growing allergic potential of today's patient cohort [14]. The mechanical properties of resin composite luting materials (e.g., microhardness) are also affected by the achieved DC $[15,16]$. With low mechanical properties hampering the overall stability and long-term success of the restoration [2], the present study aimed to investigate the mechanical and chemical properties of different dual-polymerizing resin composite luting materials over time.

For this purpose, the DC, Martens hardness (HM), elastic indentation modulus $\left(\mathrm{E}_{\mathrm{IT}}\right.$ ), and biaxial flexural strength (BFS) of six dual-polymerizing resin composite luting materials with different chemical compositions were examined. The aim of this investigation was to investigate, whether these materials showed different characteristics in the course of time. The tested hypotheses stated that neither the use of different resin composite luting materials nor the aging interval showed an impact on $\mathrm{DC}, \mathrm{HM}, \mathrm{E}_{\mathrm{IT}}$, or BFS.

\section{Materials and methods}

$\mathrm{DC}, \mathrm{HM}, \mathrm{E}_{\mathrm{IT}}$, and BFS of six different dual-polymerizing resin composite luting materials were examined initially, after 2 days and after 7 days of aging (Fig. 1, Table 1).

\section{Specimen preparation}

Each specimen was fabricated using a hollow acrylonitrile butadiene styrene mold (SD Mechatronik GmbH, Feldkirchen-Westerham, Germany) to create round discs (diameter $12 \mathrm{~mm}$, thickness $1.5 \mathrm{~mm}$ ). Before injecting the different resin composite materials, the mold was isolated using petroleum jelly (Vaselinum, Fagron GmbH, Barsbüttel, Germany). To simulate clinically relevant results, all luting materials were light-polymerized (Elipar S10, $3 \mathrm{M}$, Seefeld, Germany) through a silicate ceramic disc of $1 \mathrm{~mm}$ thickness. The discs $(n=72)$ were cut from a presintered CAD/CAM blank (Celtra Duo, Shade A2, HT, Dentsply Sirona, Charlotte, USA) using a low-speed diamond saw (Secotom-50 with cutting disc M1D13, Struers, Ballerup, Denmark; rotational speed of $2500 \mathrm{rpm}$, feed speed of $0.05 \mathrm{~mm} / \mathrm{s}$ ) under constant water cooling. Afterwards, the discs were sintered (LHT 02/16, Nabertherm GmbH, Lilienthal, Germany) according to the manufacturers'

\section{Time-dependent degree of conversion, Martens parameters and flexural strength of different dual-polymerizing resin composite luting materials}

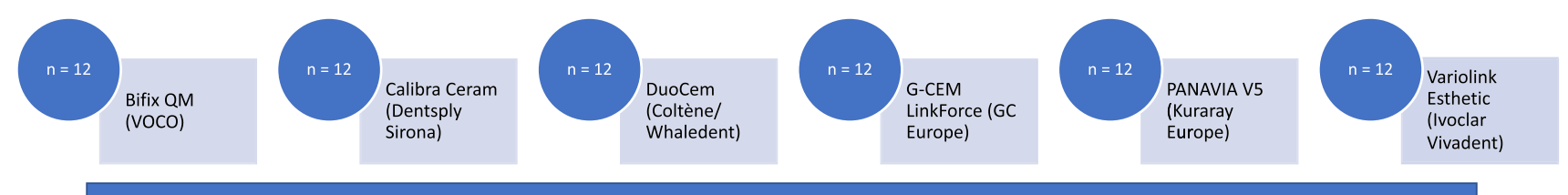

Light-curing (Elipar, 3M) through $1 \mathrm{~mm}$ restauration material (Celtra Duo, Dentsply Sirona) according to manufacturers' instructions

Degree of conversion, Martens hardness, elastic indentation modulus

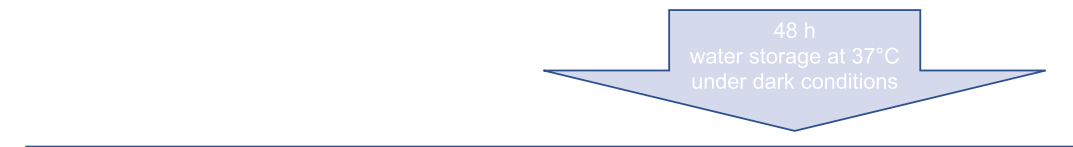

Degree of conversion, Martens hardness, elastic indentation modulus

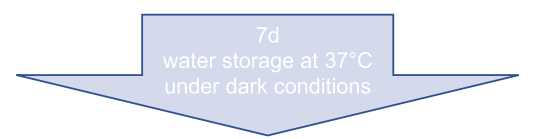

Fig. 1 Study design 
Table 1 Material, abbreviation, manufacturer, LOT. no, processing guidelines, and composition of the resin composite luting materials used

\begin{tabular}{|c|c|c|c|c|c|}
\hline Material & Abbreviation & Manufacturer & LOT.no & Processing guidelines & Chemical composition* \\
\hline Bifix QM & BIF & $\begin{array}{l}\text { VOCO, Cuxhaven, } \\
\text { Germany }\end{array}$ & $1,938,109$ & $20 \mathrm{~s}$ light-polymerization & $\begin{array}{l}10-25 \% \text { Bis-GMA, } 10-25 \% \text { 1,6-hex- } \\
\text { anediylbismethacrylate, } \leq 2.5 \% \\
\text { catalyst }\end{array}$ \\
\hline Calibra Ceram & CAL & $\begin{array}{l}\text { Dentsply Sirona, Char- } \\
\text { lotte, USA }\end{array}$ & $00,023,656$ & $20 \mathrm{~s}$ light-polymerization & $\begin{array}{l}2.5-<10 \% \text { PENTA, } 2.5-<10 \% \\
\text { UDMA, } 2.5-<10 \% \text { urethane- } \\
\text { modified Bis-GMA dimethacrylate } \\
\text { resin, } 2.5-<10 \% \text { TMPTMA, } \\
2.5-<10 \% \text { TEDMA, } 0.1-<1 \% \\
\alpha, \alpha-\text { dimethylbenzyl hydroperoxide, } \\
0.1-<1 \% \text { acrylic acid }\end{array}$ \\
\hline DuoCem & DUO & $\begin{array}{l}\text { Coltène/Whaledent, } \\
\text { Altstätten, Switzer- } \\
\text { land }\end{array}$ & $\mathrm{J} 35265$ & $20 \mathrm{~s}$ light-polymerization & $\begin{array}{l}10-<15 \% \text { Bis-GMA, } 5-<10 \% \\
\text { TEGDMA, } 1-<5 \% \text { coated zinc } \\
\text { oxide, }<1 \% \text { dibenzoyl peroxide, } \\
\text { benzoyl peroxide, }<1 \% \text { sodium } \\
\text { fluoride }\end{array}$ \\
\hline G-CEM Linkforce & GCE & $\begin{array}{l}\text { GC Europe, Leuven } \\
\text { Belgium }\end{array}$ & $1,908,081$ & $20 \mathrm{~s}$ light-polymerization & $\begin{array}{l}\text { Paste A: } 20-25 \% \text { UDMA, 5-10\% } \\
\text { dimethacrylate, }<0.5 \% \text { stabi- } \\
\text { lizer; Paste B: 20-25\% UDMA, } \\
\text { 5-10\% Bis-EMA, 5-10\% dimeth- } \\
\text { acrylate, }<1 \% \text { dibenzoyl perox- } \\
\text { ide, }<0.5 \% \text { initiator, }<0.5 \% \text { BHT }\end{array}$ \\
\hline PANAVIA V5 & PAN & $\begin{array}{l}\text { Kuraray Europe, Okay- } \\
\text { ama, Japan }\end{array}$ & 730,107 & $10 \mathrm{~s}$ light-polymerization & $\begin{array}{l}\text { 5-15\% Bis-GMA, }<5 \% \text { TEGDMA, } \\
\text { silanated barium glass filler, } \\
\text { silanated fluoroalminosilicate glass } \\
\text { filler, colloidal silica, surface- } \\
\text { treated aluminum oxide filler, } \\
\text { hydrophobic aromatic dimeth- } \\
\text { acrylate, hydrophilic aliphatic } \\
\text { dimethacrylate, dl-Camphorqui- } \\
\text { none, initiators, accelerators, } \\
\text { pigments }\end{array}$ \\
\hline Variolink Esthetic DC & VAR & $\begin{array}{l}\text { Ivoclar Vivadent, } \\
\text { Schaan, Liechtenstein }\end{array}$ & Y42678 & $\begin{array}{l}10 \mathrm{~s} \text { light-polymerization } \\
\text { per mm ceramic }\end{array}$ & $\begin{array}{l}10-<25 \% \text { ytterbium trifluoride, } \\
3-<10 \% \text { UDMA, } 3-<10 \% \\
1,10 \text {-decandiol dimethacrylate, } \\
1-<2.5 \% \alpha, \alpha \text {-dimethylbenzyl } \\
\text { hydroperoxide }\end{array}$ \\
\hline
\end{tabular}

*As provided by the manufacturer

Bis-GMA bisphenol A-glycidyl methacrylate, PENTA dipentaerythritol pentaacrylate phosphate, UDMA urethane dimethacrylate, TMPTMA propylidynetrimethyl trimethacrylate, TEDMA triethylene glycol dimethacrylate, TEGDMA triethylene glycol dimethacrylate, Bis-EMA ethoxylated bisphenol A dimethacrylate, BHT butylated hydroxytoluene

instructions. For each resin composite luting material, polymerization was performed one by one and from one side according to the manufacturers' recommendations (Table 1) using a new silicate ceramic disc. Before further processing, the surface of each specimen was cleaned with 96\% ethanol (Otto Fischar GmbH, Saarbrücken, Germany).

\section{Aging procedures}

Measurements were conducted at 3 different aging intervals:

i) Initial, directly after fabrication, dry at room temperature

ii) After 2 days of distilled water storage in an incubator (HeraCell 150 , Heraeus, Hanau, Germany) at $37^{\circ} \mathrm{C}$ under dark conditions iii) After 7 days of distilled water storage in an incubator (HeraCell 150) at $37^{\circ} \mathrm{C}$ under dark conditions.

\section{Measurement of the degree of conversion}

DC was determined using a Raman spectrophotometer (inVia Qontor, Renishaw, New Mills, UK). In the first step, the unpolymerized resin composite luting materials were directly applied on a microscope slide to record the Raman scattering of the unpolymerized material $\left(R_{\text {unpolymerized }}\right)$. Ten measurements were performed for each material to obtain an average value for $R_{\text {unpolymerized }}$ Raman spectra of the light-polymerized specimens $\left(\mathrm{R}_{\text {polymerized }}\right)$ were recorded at all aging intervals. The single mode laser operated at 
a wavelength of $785 \mathrm{~nm}$. After calibration of the system, Raman scattering was measured with $100 \%$ laser power and an irradiation time of $10 \mathrm{~s}$. The obtained data were processed using WiRE 4.4 software (Renishaw). Band heights at peaks $1610 \mathrm{~cm}^{-1}$ and $1640 \mathrm{~cm}^{-1}$ were automatically determined by the software using curve fit function (Fig. 2). DC was calculated as follows:

$\mathrm{DC}(\%)=100^{*}\left[1-\frac{R_{\text {polymerized }}}{R_{\text {unpolymerized }}}\right]$, where $R=\frac{\text { band height at } 1640 \mathrm{~cm}^{-1}}{\text { band height at } 1610 \mathrm{~cm}^{-1}}$.

\section{Measurement of Martens hardness and elastic indentation modulus}

$\mathrm{HM}$ and $\mathrm{E}_{\mathrm{IT}}$ were determined at each aging interval using the universal testing machine (Zwick/Roell ZHU 0.2, ZwickRoell, Ulm, Germany). The mounted diamond indenter (Vickers pyramid) was vertically pressed into the specimens' surface. All specimens were loaded with $9.8 \mathrm{~N}$ for $2 \mathrm{~s}$. HM and $\mathrm{E}_{\mathrm{IT}}$ values were determined at three different points per specimen per aging interval (TestXpert v.12.3 Master, ZwickRoell) with the following equations [17]:

$\mathrm{HM}=\frac{F}{A_{S}(h)}$

where $\mathrm{HM}$ is the Martens hardness, $F$ is the test force [N]; $A_{\mathrm{S}}(h)$ is the area of the indenter penetrating the surface at the distance $h$ from the tip $\left[\mathrm{mm}^{2}\right]$ and
$E_{\mathrm{IT}}=\left(1-v_{S}^{2}\right)\left(\frac{\sqrt[2]{A_{\mathrm{p}}\left(h_{\mathrm{c}}\right)}}{\sqrt{\pi S}}-\frac{\left(1-v_{\mathrm{i}}^{2}\right)}{E_{\mathrm{i}}}\right)^{-1}$

where $E_{\mathrm{i}}$ is the elastic modulus of the indenter $\left[\mathrm{N} / \mathrm{mm}^{2}\right]$, $A_{\mathrm{p}}\left(h_{\mathrm{c}}\right)$ the projected contact area under load $\left[\mathrm{mm}^{2}\right], v_{\mathrm{s}}$ is the Poisson's ratio of the specimen with $v_{\mathrm{s}}=0.4$ [18], $v_{\mathrm{i}}$ is the Poisson's ratio of the indenter with $v_{\mathrm{i}}=0.3$, and $S$ the contact stiffness evaluated from the force removal curve [19].

\section{Measurement of flexural strength}

At the final aging interval, specimens were subjected to a biaxial flexural strength measurement at a room temperature of $23{ }^{\circ} \mathrm{C}$ using the universal testing machine (Zwick/Roell Z010, Zwick/Roell, Ulm, Germany) with a load cell capacity of $250 \mathrm{~N}$. The thickness of each specimen was determined with a digital micrometer screw with an accuracy of $\pm 4 \mu \mathrm{m}$ (IP65, Mitutoyo Deutschland, Neuss, Germany) prior to placement on a jig with a piston on three balls design. The tempered steel balls forming an equilateral triangle had a diameter of $3.2 \mathrm{~mm}$. Loading with a crosshead speed of $1 \mathrm{~mm} / \mathrm{min}$ was applied with a $1.6 \mathrm{~mm}$ diameter plunger in the center of each specimen until failure. Biaxial flexural strength was calculated using two decimal places and the following formula [20]:

$\sigma=0.2387 P^{*}(X-Y) / d^{2}$

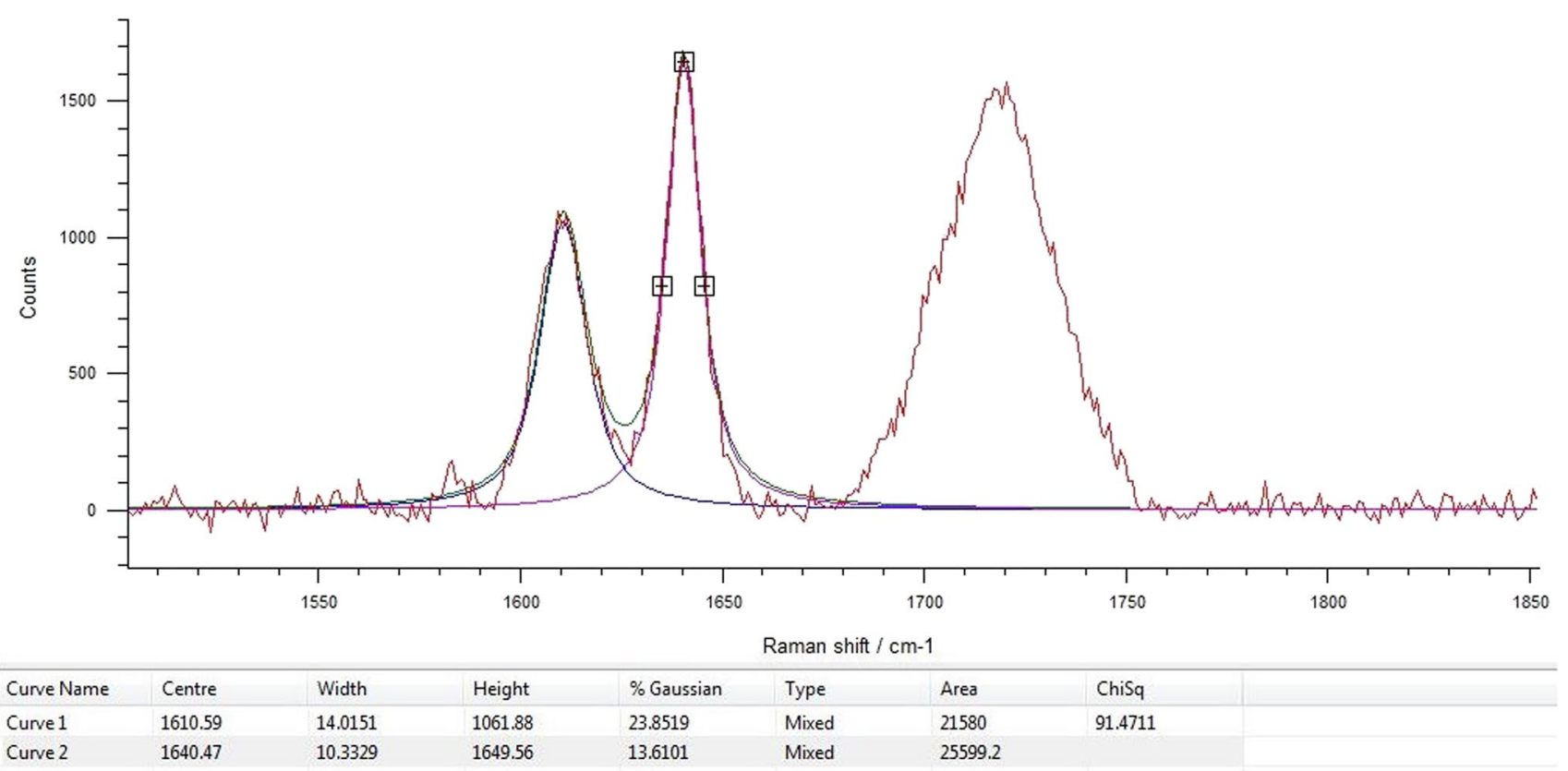

Fig. 2 Raman spectrum with peaks at $1610 \mathrm{~cm}^{-1}$ and $1640 \mathrm{~cm}^{-1}$ (DuoCem, Coltene/Whaledent AG) 
where $\sigma$ is BFS, $P$ is fracture load $[\mathrm{N}], d$ is specimen thickness [mm], and the coefficients $X$ and $Y$ :

$X=(1+v) \ln [(r 2 / r 3)]^{2}+[(1-v) / 2](r 2 / r 3)^{2}$

$Y=(1+v)\left[1+\ln \left[(r 1 / r 3)^{2}\right]+(1-v)(r 1 / r 3)^{2}\right.$

with $v$ is Poisson's ratio $(v=0.4), r_{1}$ is the radius of the support circle formed by the three tempered steel balls [mm], $r_{2}$ is the radius of the loaded area [mm], and $r_{3}$ is the specimen radius $[\mathrm{mm}]$.

\section{Statistical analysis}

Descriptive statistics were computed (IBM SPSS Statistics v25.0, IBM Corp, NY, USA). The assumption of normality was tested with the Kolmogorov-Smirnov test. For general analysis, univariate ANOVAs with partial eta squared $\left(\eta_{\mathrm{p}}{ }^{2}\right)$ and Scheffé's post hoc test were computed. To figure out significant differences between the groups' non-parametric analysis, Kruskal-Wallis, Mann-Whitney $U$, Friedman, and Wilcoxon tests were performed. For a better understanding of the reliability of the tested materials, Weibull modulus was calculated using the maximum likelihood estimation method and 95\% confidence interval [21]. For all statistical analyses, $p<0.05$ were interpreted as statistically significant.

\section{Results}

The results of the descriptive statistics are displayed in Tables 2 and 3. With the Kolmogorov-Smirnov test showing a violation of the assumption of normality for DC (11\% not normally distributed), HM (17\% not normally distributed), $\mathrm{E}_{\mathrm{IT}}(17 \%$ not normally distributed), and BFS (17\% not normally distributed), non-parametric tests were carried out. The resin composite luting material showed the highest influence (DC: $p<0.001, \eta_{\mathrm{p}}{ }^{2}=0.864$; HM: $p<0.001$, $\left.\eta_{\mathrm{p}}{ }^{2}=0.836 ; \mathrm{E}_{\mathrm{IT}}: p<0.001, \eta_{\mathrm{p}}{ }^{2}=0.634\right)$, followed by the aging interval (DC: $p<0.001, \eta_{\mathrm{p}}^{2}=0.188$; HM: $p<0.001$, $\left.\eta_{\mathrm{p}}{ }^{2}=0.078 ; \mathrm{E}_{\mathrm{IT}}: p<0.001, \eta_{\mathrm{p}}{ }^{2}=0.065\right)$. As the interactions between resin composite luting material and aging showed an impact on $\mathrm{HM}\left(p=0.028, \eta_{\mathrm{p}}{ }^{2}=0.095\right)$ and $\mathrm{E}_{\mathrm{IT}}(p=0.055$,
Table 2 Degree of conversion, Martens hardness $\left[\mathrm{N} / \mathrm{mm}^{2}\right]$, and elastic indentation modulus $\left[\mathrm{kN} / \mathrm{mm}^{2}\right]$ for all tested groups

\begin{tabular}{|c|c|c|c|c|c|c|}
\hline & DC & & $\mathrm{HM}$ & & $\mathrm{E}_{\mathrm{IT}}$ & \\
\hline & Mean $( \pm$ SD $)$ & $95 \% \mathrm{CI}$ & Mean $( \pm S D)$ & $95 \% \mathrm{CI}$ & Mean $( \pm \mathrm{SD})$ & $95 \% \mathrm{CI}$ \\
\hline \multicolumn{7}{|l|}{ i) Initial } \\
\hline BIF & $70.0 \pm 2.89^{\mathrm{d}, \mathrm{A}}$ & {$[68.0 ; 71.9]$} & $314 \pm 55.6^{* \mathrm{~d}, \mathrm{~A}}$ & {$[277 ; 349]$} & $7.40 \pm 1.74^{\mathrm{c}, \mathrm{A}}$ & {$[6.28 ; 8.51]$} \\
\hline CAL & $39.9 \pm 2.83^{\mathrm{a}, \mathrm{A}}$ & {$[37.9 ; 41.7]$} & $113 \pm 28.0^{\mathrm{a}, \mathrm{A}}$ & {$[94 ; 131]$} & $3.38 \pm 0.90^{\mathrm{a}, \mathrm{A}}$ & {$[2.79 ; 3.96]$} \\
\hline DUO & $69.5 \pm 2.08^{\mathrm{d}, \mathrm{A}}$ & {$[68.0 ; 70.9]$} & $236 \pm 20.7^{\mathrm{c}, \mathrm{A}}$ & {$[221 ; 249]$} & $6.68 \pm 1.06^{\mathrm{c}, \mathrm{A}}$ & {$[5.99 ; 7.36]$} \\
\hline GCE & $71.3 \pm 2.35^{\mathrm{d}, \mathrm{A}}$ & {$[69.6 ; 72.8]$} & $220 \pm 37.9^{\mathrm{c}, \mathrm{A}}$ & {$[194 ; 244]$} & $5.27 \pm 1.60^{\mathrm{b}, \mathrm{A}}$ & {$[4.24 ; 6.29]$} \\
\hline PAN & $51.6 \pm 6.18^{\mathrm{b}, \mathrm{A}}$ & {$[47.5 ; 55.5]$} & $127 \pm 24.6^{\mathrm{a}, \mathrm{A}}$ & {$[110 ; 143]$} & $3.87 \pm 1.04^{\mathrm{ab}, \mathrm{A}}$ & {$[3.19 ; 4.54]$} \\
\hline VAR & $58.9 \pm 4.23^{\mathrm{c}, \mathrm{A}}$ & {$[56.1 ; 61.7]$} & $149 \pm 21.9^{\mathrm{b}, \mathrm{A}}$ & {$[134 ; 164]$} & $4.04 \pm 0.89^{\mathrm{ab}, \mathrm{A}}$ & {$[3.46 ; 4.61]$} \\
\hline \multicolumn{7}{|c|}{ ii) After 2 days } \\
\hline BIF & $73.2 \pm 5.32^{\mathrm{d}, \mathrm{B}}$ & {$[69.7 ; 76.6]$} & $377 \pm 67.1 * \mathrm{f}, \mathrm{B}$ & {$[333 ; 420]$} & $9.04 \pm 2.51^{\mathrm{d}, \mathrm{A}}$ & {$[7.43 ; 10.7]$} \\
\hline CAL & $44.1 \pm 4.79^{\mathrm{a}, \mathrm{B}}$ & {$[40.9 ; 47.2]$} & $103 \pm 20.9^{\mathrm{a}, \mathrm{A}}$ & {$[89 ; 117]$} & $3.13 \pm 0.65^{\mathrm{a}, \mathrm{A}}$ & {$[2.70 ; 3.55]$} \\
\hline DUO & $72.2 \pm 3.18^{\mathrm{d}, \mathrm{B}}$ & {$[70.0 ; 74.2]$} & $270 \pm 25.5^{\mathrm{e}, \mathrm{B}}$ & {$[252 ; 287]$} & $7.71 \pm 1.55^{* \mathrm{~d}, \mathrm{~B}}$ & {$[6.71 ; 8.70]$} \\
\hline GCE & $75.4 \pm 2.69^{\mathrm{d}, \mathrm{B}}$ & {$[73.6 ; 77.2]$} & $217 \pm 54.3^{\mathrm{d}, \mathrm{A}}$ & {$[181 ; 252]$} & $5.29 \pm 1.94 * \mathrm{bc}, \mathrm{A}$ & {$[4.04 ; 6.52]$} \\
\hline PAN & $56.6 \pm 5.78^{\mathrm{b}, \mathrm{B}}$ & {$[52.8 ; 60.3]$} & $144 \pm 30.0^{\mathrm{b}, \mathrm{B}}$ & {$[124 ; 164]$} & $4.21 \pm 1.08^{\mathrm{b}, \mathrm{A}}$ & {$[3.51 ; 4.90]$} \\
\hline VAR & $64.6 \pm 6.08^{\mathrm{c}, \mathrm{B}}$ & {$[60.6 ; 68.5]$} & $178 \pm 23.3^{\mathrm{c}, \mathrm{B}}$ & {$[161 ; 193]$} & $5.44 \pm 0.82^{\mathrm{c}, \mathrm{B}}$ & {$[4.90 ; 5.97]$} \\
\hline \multicolumn{7}{|c|}{ iii) After 7 days } \\
\hline $\mathrm{BIF}$ & $71.7 \pm 3.39^{\mathrm{d}, \mathrm{B}}$ & {$[69.4 ; 73.9]$} & $339 \pm 51.1^{\mathrm{e}, \mathrm{AB}}$ & {$[305 ; 372]$} & $7.98 \pm 1.90^{\mathrm{d}, \mathrm{A}}$ & {$[6.75 ; 9.19]$} \\
\hline CAL & $45.1 \pm 7.18^{* \mathrm{a}, \mathrm{B}}$ & {$[40.4 ; 49.7]$} & $113 \pm 17.1^{\mathrm{a}, \mathrm{A}}$ & {$[101 ; 125]$} & $3.19 \pm 0.58^{\mathrm{a}, \mathrm{A}}$ & {$[2.80 ; 3.56]$} \\
\hline DUO & $72.7 \pm 3.48^{\mathrm{d}, \mathrm{B}}$ & {$[70.4 ; 75.0]$} & $269 \pm 23.8^{* \mathrm{~d}, \mathrm{~B}}$ & {$[252 ; 285]$} & $8.28 \pm 0.96^{* \mathrm{~d}, \mathrm{~B}}$ & {$[7.65 ; 8.89]$} \\
\hline GCE & $75.2 \pm 2.11 * \mathrm{~d}, \mathrm{~B}$ & {$[73.7 ; 76.6]$} & $221 \pm 42.2^{\mathrm{c}, \mathrm{A}}$ & {$[193 ; 248]$} & $5.23 \pm 1.44^{\mathrm{bc}, \mathrm{A}}$ & {$[4.30 ; 6.15]$} \\
\hline PAN & $57.4 \pm 5.47^{\mathrm{b}, \mathrm{B}}$ & {$[53.8 ; 60.9]$} & $150 \pm 32.2^{\mathrm{b}, \mathrm{B}}$ & {$[128 ; 171]$} & $4.54 \pm 1.39^{\mathrm{b}, \mathrm{A}}$ & {$[3.64 ; 5.43]$} \\
\hline VAR & $67.3 \pm 6.73^{\mathrm{c}, \mathrm{B}}$ & {$[62.9 ; 71.7]$} & $191 \pm 15.7^{\mathrm{c}, \mathrm{B}}$ & {$[180 ; 202]$} & $6.06 \pm 1.10^{\mathrm{c}, \mathrm{B}}$ & {$[5.34 ; 6.76]$} \\
\hline
\end{tabular}

*Not normally distributed

${ }^{a b c}$ Different letters present significant differences between resin composite luting materials within one aging interval

${ }^{\mathrm{ABC}}$ Different letters present significant differences between aging intervals within one resin composite luting material 
Table 3 Flexural strength and Weibull moduli for all tested groups

\begin{tabular}{lllll}
\hline & \multicolumn{2}{l}{ Flexural strength } & \multicolumn{2}{l}{ Weibull modulus } \\
\hline & Mean $( \pm$ SD) & $95 \%$ CI & $m$ & $95 \%$ CI \\
BIF & $126 \pm 48.1^{\mathrm{bc}}$ & {$[95.3 ; 157]$} & $0.6^{\mathrm{a}}$ & {$[0.2 ; 1.1]$} \\
CAL & $79 \pm 18.7^{\mathrm{a}}$ & {$[67.0 ; 90.1]$} & $4.7^{\mathrm{bc}}$ & {$[2.4 ; 8.6]$} \\
DUO & $122 \pm 11.4^{\mathrm{c}}$ & {$[114 ; 130]$} & $12.3^{\mathrm{d}}$ & {$[6.7 ; 22.4]$} \\
GCE & $125 \pm 42.9^{\mathrm{bc}}$ & {$[97.5 ; 153]$} & $2.5^{\mathrm{b}}$ & {$[1.2 ; 4.6]$} \\
PAN & $134 \pm 28.8^{* \mathrm{c}}$ & {$[114 ; 152]$} & $6.1^{\mathrm{c}}$ & {$[3.2 ; 11.0]$} \\
VAR & $108 \pm 12.2^{\mathrm{b}}$ & {$[99.0 ; 117]$} & $10.7^{\mathrm{cd}}$ & {$[5.8 ; 19.5]$} \\
\hline
\end{tabular}

*Not normally distributed

${ }^{a b c}$ Different letters present significant differences between resin composite luting materials

$\eta_{\mathrm{p}}{ }^{2}=0.085$ ), data were analyzed separately according to the tested hypotheses.

Within one aging interval, CAL showed the lowest DC, followed by PAN and VAR $(\mathrm{p}<0.001)$. DUO, BIF, and GCE presented the highest DC $(\mathrm{p}<0.001)$, with no significant differences being observed between the three materials $(p=0.369-0.999)$. Values for the DC increased after the initial measurement $(p<0.001)$, while no difference between aging for 2 or 7 days could be detected $(\mathrm{p}=0.767)$ (Fig. 3).
Initially, the lowest $\mathrm{HM}$ was observed in the groups $\mathrm{CAL}$ and PAN $(\mathrm{p}<0.001)$, while the lowest $\mathrm{E}_{\mathrm{IT}}$ values were recorded for CAL, PAN, and VAR $(\mathrm{p}<0.001)$. After 2 or 7 days of aging, the lowest values for $\mathrm{HM}$ and $\mathrm{E}_{\mathrm{IT}}$ were found for CAL specimens $(\mathrm{p}=0.001-0.017)$. Regardless of the aging interval, BIF led to the highest HM results ( $\mathrm{p}=0.001-0.003)$, while BIF and DUO presented the highest $\mathrm{E}_{\mathrm{IT}}$ values $(\mathrm{p}<0.001)$. Looking at the effect of aging, an increase in values between the initial measurement and aging for 2 or 7 days was observed for HM values of BIF, DUO, PAN, and VAR $(\mathrm{p}=0.001-0.017)$ and $\mathrm{E}_{\mathrm{IT}}$ results of DUO and VAR ( $\mathrm{p}=0.001$ ) (Figs. 4 and 5).

The choice of resin composite luting material presented an influence on the BFS, with CAL showing the lowest BFS values, while BIF, DUO, GCE, and PAN demonstrated the highest results $(p<0.001)$. When regarding the Weibull modulus, the lowest value was observed for BIF, while VAR and DUO presented the highest Weibull modulus.

\section{Discussion}

The aim of this investigation was to examine the DC, HM, $\mathrm{E}_{\mathrm{IT}}$, and BFS of six dual-polymerizing resin composite luting materials after aging. The tested hypotheses that neither
Fig. 3 Degree of conversion of the different resin composite luting materials over the course of the three aging intervals

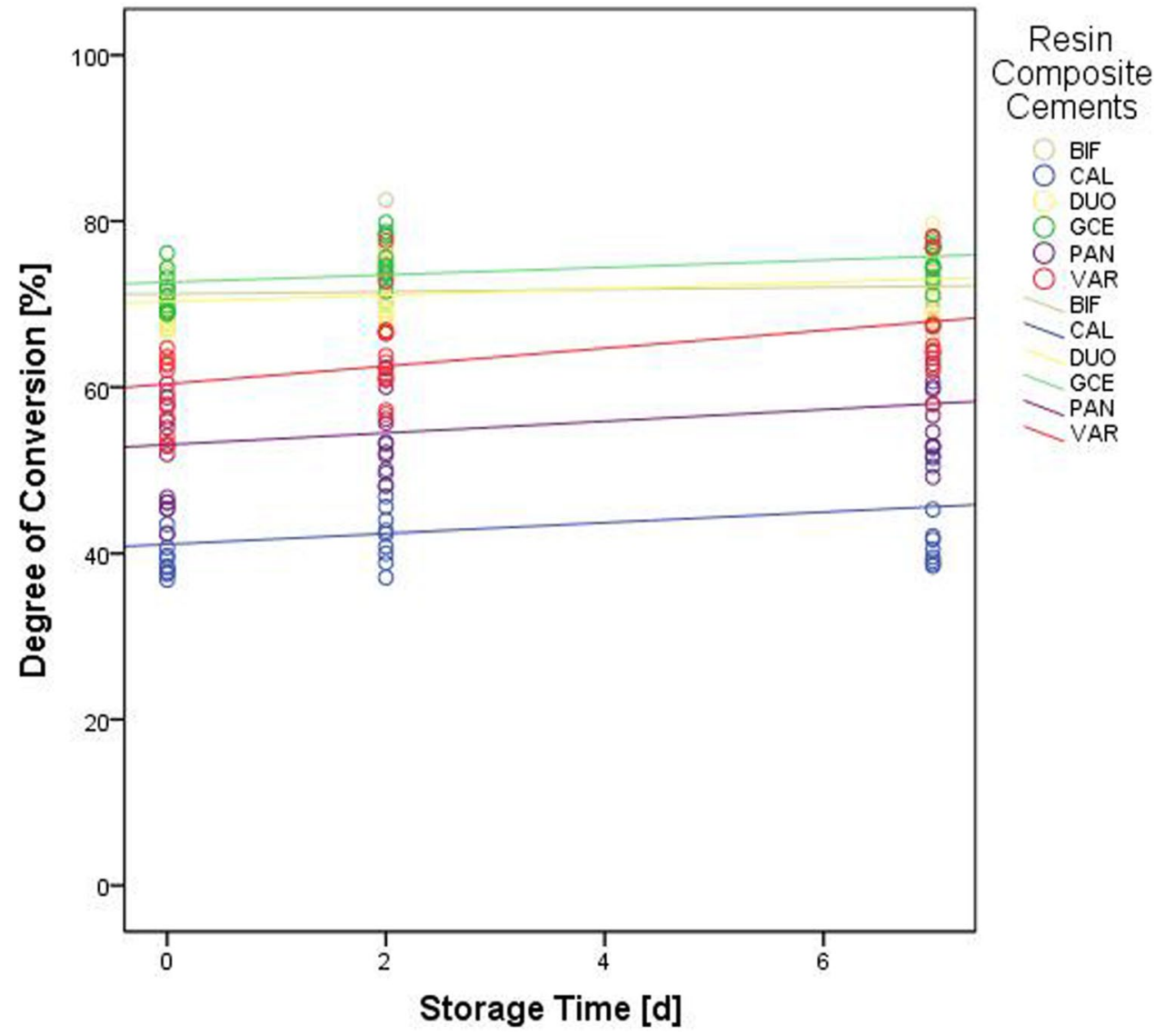


Fig. 4 Martens hardness of the different resin composite luting materials over the course of the three aging intervals

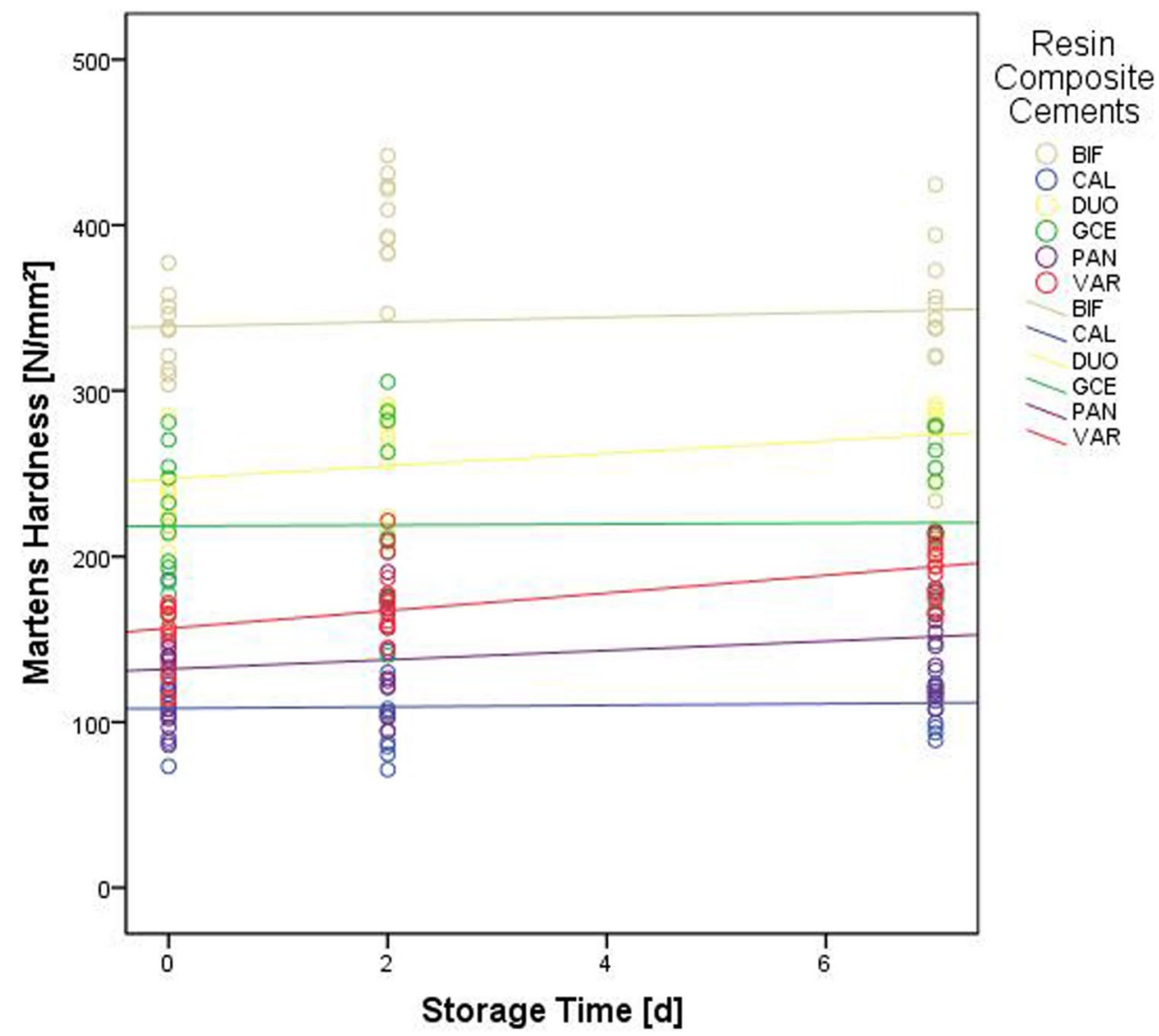

the use of different resin composite luting materials nor the aging interval showed an impact on $\mathrm{DC}, \mathrm{HM}, \mathrm{E}_{\mathrm{IT}}$, or BFS had to be rejected.

The polymerization reaction of dual-polymerizing resin composite luting materials, induced by both photo and chemical initiators, leads to an increasing viscosity of the luting material that hinders the movement of the reactive species until conversion comes to a standstill. In the present study, values for the DC of the resin composite luting materials ranged between 39.9 and 75.4. This value range corresponds with previous investigations examining dualpolymerizing resin luting materials with Fourier transform infrared spectroscopy $[22,23]$. CAL showed the lowest DC, DUO, and BIF and GCE presented the highest values. With the manufacturers only providing limited information about the chemical composition of the different materials, an interpretation of the influence of the amount and ratio of photo (e.g., camphor quinone) and self-polymerizing initiators (e.g., benzoyl peroxide), their interaction with polymerization inhibitors and fillers, and the composition of the polymer matrix on the results of the present study is complex. Previous investigations employing Fourier transform Raman spectroscopy have reported an impact of the bisphenol A-glycidyl methacrylate (Bis-GMA) and co-monomer content on the degree of conversion [24]. A high DC was observed for the monomer triethylene glycol dimethacrylate (TEGDMA), while Bis-GMA presented significantly lower values [25]. When regarding the contained fillers, it becomes apparent that PAN is the only material where the manufacturer indicated an inclusion of glass fillers in the resin composite luting material's composition. A positive correlation between a high amount of fillers on the one hand and a low degree of conversion on the other hand has been reported previously [26, 27]. As PAN presented average values by comparison with the examined unfilled materials in the present investigation, future studies will have to examine in how far the filler content plays a crucial part in the DC of dual-polymerizing resin composite luting materials. The duration of light-polymerization may play a negligible role, as CAL presented lower DC values than PAN and VAR, although the duration of light-polymerization was twice as long. As previous examinations did, however, observe an increased light-polymerization time, even above the manufacturers' instructions, to increase polymerization [28-30], future studies should investigate the influence of varying light-polymerization durations on the degree of conversion of the tested resin composite luting materials. Values for the DC and the Martens parameters increased between the initial measurement and aging for 2 days, while aging for 7 days provided no further improvement. This is in line with 
Fig. 5 Elastic indentation modulus of the different resin composite luting materials over the course of the three aging intervals

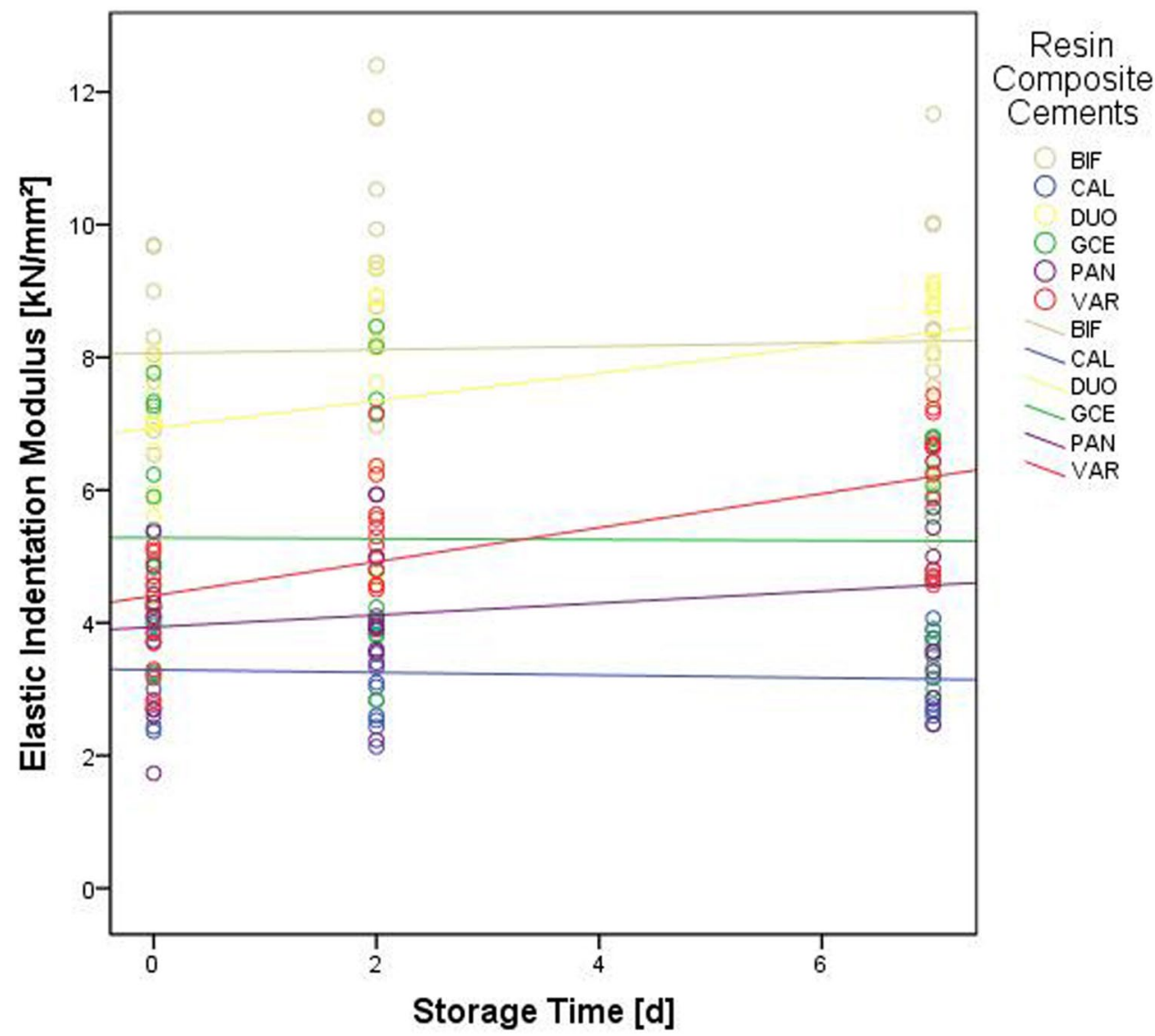

previous investigations reporting a high initial increase of the DC immediately after light exposure, followed by a much slower increase in the ensuing hours [31,32]. When comparing different materials, the level of initial conversion attained from exposure to the polymerization device has furthermore been observed to be a highly influential factor in the final polymerization of light- or dual-polymerized materials $[25,33]$

Although future studies are warranted to confirm the present results, these findings indicate the completion of the polymerization reaction, and in consequence the achieved maximum stability of the luting material and dental restoration, to take up to $48 \mathrm{~h}$. This parameter may be of clinical importance for practicing dentists instructing patients with regard to their postoperative behavior (e.g., avoiding extensive loading in the restored region). It could furthermore alter subsequent treatment procedures, as the present findings clearly indicate an ongoing chemical reaction taking place in the tested dual-polymerizing resin composite luting materials over time. In the case of imperative additional impressions with high-viscosity materials, this procedure should, if feasible, be postponed to a later time, when the polymerization reaction is completed. In line with the observed results for the DC, CAL presented low $\mathrm{HM}$ and $\mathrm{E}_{\mathrm{IT}}$ values, while high values were reported for DUO and BIF. This was to be expected as numerous studies have reported a positive correlation between the DC and the mechanical properties of resin composites $[15,16]$. The same trend was seen for the BFS values, where CAL once again presented the lowest values, while DUO, BIF, GCE, and PAN demonstrated the highest results. The computation of the Weibull moduli did, however, yield BIF to present the lowest value, while VAR and DUO presented the highest reliability. While further in vitro and in vivo studies are needed to confirm these results, the present findings indicate the preferred use of resin composite luting material DUO, characterized by a clinically practical light-polymerization duration of $20 \mathrm{~s}$, as it demonstrated significantly highest and reliable results regarding the DC, Martens parameters, and BFS.

The observed results do, however, have to be considered in regard to the limitations of this in vitro investigation, which include a slight variation in the time period between the light-polymerization of each specimen and the measurement of the tested parameters due to the study set-up. Uniform light-polymerization times could allow the elaboration of differences between the tested materials solely based on their composition. In the present study, polymerization was performed through a zirconia reinforced lithium silicate ceramic to imitate the clinical situation as accurately 
as possible. While this study set-up has been established in numerous previous investigations [23, 34, 35], the choice of ceramic holds a significant impact on the ongoing polymerization reaction, as the ceramic's crystal structure defines how much light reaches the photo initiators of the resin composite luting material $[15,34]$. In this context, the thickness of the employed ceramic also plays a vital part [34]. As in previous investigations, discs of $1 \mathrm{~mm}$ thickness were chosen to allow an optimal comparison of the obtained results [15, $23,35]$. Future studies should furthermore examine potential differences in a resin composite luting material's chemical and mechanical properties following light-polymerization in comparison with self-polymerization. To assess the behavior of resin composite luting materials over time, dynamic testing protocols should be included in future study designs. Clinical investigations should furthermore examine a wider range of ceramic and resin composite luting materials to confirm the results of the present in-vitro investigation. While the determination of the degree of conversion and Martens parameters provides valuable information regarding a material's biocompatibility and mechanical properties, additional factors such as the esthetic outcome [36], the achieved bond strength [37] and the resulting polymerization stress [38] should be taken into consideration when choosing a resin composite luting material.

\section{Conclusions}

Within the limitations of this study, the following conclusions can be drawn:

1. The dual-polymerizing resin composite luting material DUO may be recommended for luting fixed dental prostheses as it demonstrated significantly highest and reliable results regarding the degree of conversion, Martens parameters, and biaxial flexural strength.

2. As the degree of conversion and the Martens parameters of the tested resin composite luting materials increased between the initial measurement and the simulated clinical condition after $48 \mathrm{~h}$, the completion of the polymerization reaction, which is of practical importance to both dentists and patients, may be deferred.

Acknowledgements The authors would like to thank Ivoclar Vivadent, GC Europe, Kuraray Europe, Dentsply Sirona, VOCO, and Coltène/ Whaledent for supporting this study with materials

Funding Open Access funding enabled and organized by Projekt DEAL. This research was supported by the German Research Foundation DFG (INST 409/190-1 FUGG contract) in the field of Raman spectrometry.

\section{Declarations}

Ethical approval This article does not contain any studies with human participants or animals performed by any of the authors.

Informed consent For this type of study, formal consent is not required.

Conflict of interest The authors declare no competing interests.

Open Access This article is licensed under a Creative Commons Attribution 4.0 International License, which permits use, sharing, adaptation, distribution and reproduction in any medium or format, as long as you give appropriate credit to the original author(s) and the source, provide a link to the Creative Commons licence, and indicate if changes were made. The images or other third party material in this article are included in the article's Creative Commons licence, unless indicated otherwise in a credit line to the material. If material is not included in the article's Creative Commons licence and your intended use is not permitted by statutory regulation or exceeds the permitted use, you will need to obtain permission directly from the copyright holder. To view a copy of this licence, visit http://creativecommons.org/licenses/by/4.0/.

\section{References}

1. Edelhoff D, Stimmelmayr M, Schweiger J, Ahlers MO, Guth JF (2019) Advances in materials and concepts in fixed prosthodontics: a selection of possible treatment modalities. Br Dent J 226:739-748. https://doi.org/10.1038/s41415-019-0265-z

2. Blatz MB, Vonderheide M, Conejo J (2018) The effect of resin bonding on long-term success of high-strength ceramics. J Dent Res 97:132-139. https://doi.org/10.1177/0022034517729134

3. Edelhoff D, Ozcan M (2007) To what extent does the longevity of fixed dental prostheses depend on the function of the cement? Working Group 4 materials: cementation. Clin Oral Implants Res 18(Suppl 3):193-204. https://doi.org/10.1111/j.1600-0501.2007. 01442.x

4. Jivraj SA, Kim TH, Donovan TE (2006) Selection of luting agents part 1. J Calif Dent Assoc 34:149-160

5. Hill EE, Lott J (2011) A clinically focused discussion of luting materials. Aust Dent J 56(Suppl 1):67-76. https://doi.org/10. 1111/j.1834-7819.2010.01297.x

6. Edelhoff D, Sorensen JA (2002) Tooth structure removal associated with various preparation designs for anterior teeth. J Prosthet Dent 87:503-509. https://doi.org/10.1067/mpr.2002.124094

7. Lad PP, Kamath M, Tarale K, Kusugal PB (2014) Practical clinical considerations of luting cements: a review. J Int Oral Health 6:116-120

8. Turkoglu P, Sen D (2019) Evaluation of dual-cure resin cement polymerization under different types and thicknesses of monolithic zirconia. Biomed Res Int 2019:4567854. https://doi.org/10. $1155 / 2019 / 4567854$

9. da Silva EM, Almeida GS, Poskus LT, Guimaraes JG (2008) Relationship between the degree of conversion, solubility and salivary sorption of a hybrid and a nanofilled resin composite. J Appl Oral Sci 16:161-166. https://doi.org/10.1590/s1678-775720080002000 15

10. Walton JN, Gardner FM, Agar JR (1986) A survey of crown and fixed partial denture failures: length of service and reasons for replacement. J Prosthet Dent 56:416-421. https://doi.org/10.1016/ 0022-3913(86)90379-3

11. Al Refai R, Saker S (2018) Clinical and radiographic assessment of reasons for replacement of metal- ceramic fixed dental 
prostheses in patients referring to dental school. J Clin Exp Dent 10:e75-e80. https://doi.org/10.4317/jced.53850

12. Koishi Y, Tanoue N, Atsuta M, Matsumura H (2002) Influence of visible-light exposure on colour stability of current dual-curable luting composites. J Oral Rehabil 29:387-393. https://doi.org/10. 1046/j.1365-2842.2002.00823.x

13. Moraes RR, Correr-Sobrinho L, Sinhoreti MA, Puppin-Rontani RM, Ogliari FA, Piva E (2008) Light-activation of resin cement through ceramic: relationship between irradiance intensity and bond strength to dentin. J Biomed Mater Res B Appl Biomater 85:160-165. https://doi.org/10.1002/jbm.b.30928

14. Gupta SK, Saxena P, Pant VA, Pant AB (2012) Release and toxicity of dental resin composite. Toxicol Int 19:225-234. https://doi. org/10.4103/0971-6580.103652

15. AlShaafi MM, AlQahtani MQ, Price RB (2014) Effect of exposure time on the polymerization of resin cement through ceramic. J Adhes Dent 16:129-135. https://doi.org/10.3290/j.jad.a30756

16. Calheiros FC, Daronch M, Rueggeberg FA, Braga RR (2008) Degree of conversion and mechanical properties of a BisGMA:TEGDMA composite as a function of the applied radiant exposure. J Biomed Mater Res B Appl Biomater 84:503-509. https://doi.org/10.1002/jbm.b.30897

17. Technical Committee ISO/TC 164, Dentistry (2015) Metallic materials (ISO 14577: 2015). Geneva: International Organization for Standardization

18. Greaves GN, Greer AL, Lakes RS, Rouxel T (2011) Poisson's ratio and modern materials. Nat Mater 10:823-837. https://doi.org/10. 1038/nmat3134

19. Hampe R, Lumkemann N, Sener B, Stawarczyk B (2018) The effect of artificial aging on Martens hardness and indentation modulus of different dental CAD/CAM restorative materials. J Mech Behav Biomed Mater 86:191-198. https://doi.org/10.1016/j. jmbbm.2018.06.028

20. Technical Committee ISO/TC 106, Dentistry (2015) Ceramic materials (ISO 6872: 2015). Geneva: International Organization for Standardization

21. Butikofer L, Stawarczyk B, Roos M (2015) Two regression methods for estimation of a two-parameter Weibull distribution for reliability of dental materials. Dent Mater 31:e33-50. https://doi. org/10.1016/j.dental.2014.11.014

22. Oliveira M, Cesar PF, Giannini M, Rueggeberg FA, Rodrigues J, Arrais CA (2012) Effect of temperature on the degree of conversion and working time of dual-cured resin cements exposed to different curing conditions. Oper Dent 37:370-379. https://doi. org/10.2341/11-198-L

23. Novais VR, Raposo LH, Miranda RR, Lopes CC, Simamoto PCJ, Soares CJ (2017) Degree of conversion and bond strength of resincements to feldspathic ceramic using different curing modes. J Appl Oral Sci 25:61-68. https://doi.org/10.1590/1678-77572 016-0221

24. Goncalves F, Kawano Y, Pfeifer C, Stansbury JW, Braga RR (2009) Influence of BisGMA, TEGDMA, and BisEMA contents on viscosity, conversion, and flexural strength of experimental resins and composites. Eur J Oral Sci 117:442-446. https://doi. org/10.1111/j.1600-0722.2009.00636.x

25. Gajewski VE, Pfeifer CS, Froes-Salgado NR, Boaro LC, Braga RR (2012) Monomers used in resin composites: degree of conversion, mechanical properties and water sorption/solubility. Braz Dent J 23:508-514. https://doi.org/10.1590/s0103-64402012000500007
26. Halvorson RH, Erickson RL, Davidson CL (2003) The effect of filler and silane content on conversion of resin-based composite. Dent Mater 19:327-333. https://doi.org/10.1016/s0109-5641(02) 00062-3

27. Mayinger F, Reymus M, Liebermann A, Richter M, Kubryk P, Groekappenberg H, Stawarczyk B (2021) Impact of polymerization and storage on the degree of conversion and mechanical properties of veneering resin composites. Dent Mater J 40(2):487-497. https://doi.org/10.4012/dmj.2019-394

28. Santos GC Jr, El-Mowafy O, Rubo JH, Santos MJ (2004) Hardening of dual-cure resin cements and a resin composite restorative cured with QTH and LED curing units. J Can Dent Assoc 70:323-328

29. Konuray O, Fernandez-Francos X, Ramis X, Serra A (2018) State of the art in dual-curing acrylate systems. Polymers (Basel) 10(2):178. https://doi.org/10.3390/polym10020178

30. Braganca GF, Vianna AS, Neves FD, Price RB, Soares CJ (2020) Effect of exposure time and moving the curing light on the degree of conversion and Knoop microhardness of light-cured resin cements. Dent Mater 36(11):e340-e351. https://doi.org/10.1016/j. dental.2020.08.016

31. Frassetto A, Navarra CO, Marchesi G, Turco G, Di Lenarda R, Breschi L, Ferracane JL, Cadenaro M (2012) Kinetics of polymerization and contraction stress development in self-adhesive resin cements. Dent Mater 28:1032-1039. https://doi.org/10.1016/j. dental.2012.06.003

32. Yan YL, Kim YK, Kim KH, Kwon TY (2010) Changes in degree of conversion and microhardness of dental resin cements. Oper Dent 35:203-210. https://doi.org/10.2341/09-174-L

33. Rueggeberg FA, Caughman WF (1993) The influence of light exposure on polymerization of dual-cure resin cements. Oper Dent 18:48-55

34. Calgaro PA, Furuse AY, Correr GM, Ornaghi BP, Gonzaga CC (2013) Influence of the interposition of ceramic spacers on the degree of conversion and the hardness of resin cements. Braz Oral Res 27:403-409. https://doi.org/10.1590/S1806-8324201300 0500004

35. Zhang X, Wang F (2011) Hardness of resin cement cured under different thickness of lithium disilicate-based ceramic. Chin Med J (Engl) 124:3762-3767

36. Kilinc E, Antonson SA, Hardigan PC, Kesercioglu A (2011) Resin cement color stability and its influence on the final shade of allceramics. J Dent 39(Suppl 1):e30-e36. https://doi.org/10.1016/j. jdent.2011.01.005

37. Stewart GP, Jain P, Hodges J (2002) Shear bond strength of resin cements to both ceramic and dentin. J Prosthet Dent 88:277-284. https://doi.org/10.1067/mpr.2002.128034

38. Wiedenmann F, Becker F, Eichberger M, Stawarczyk B (2021) Measuring the polymerization stress of self-adhesive resin composite cements by crack propagation. Clin Oral Investig 25(3):1011-1018. https://doi.org/10.1007/s00784-020-03391-5

Publisher's note Springer Nature remains neutral with regard to jurisdictional claims in published maps and institutional affiliations. 